\title{
Differentiation of Murine Uterine NK Cells in Ectopically Grafted Uterine Tissues
}

\author{
Orie NAKAMURA ${ }^{1)}$, Eiichi HONDO'1), Keiji KOKUBU ${ }^{1)}$ and Yasuo KISO') \\ 1) Department of Veterinary Anatomy, Faculty of Agriculture, Yamaguchi University, 1677-1 \\ Yoshida, Yamaguchi 753-8515, Japan
}

\begin{abstract}
To investigate whether progesterone plays an essential role in differentiation of uNK cells, we ectopically transplanted tissue grafts from different developmental stages of uteri under various conditions. When female mice were used as recipients, decidualization and differentiation of uNK cells were observed in grafts from mature ( 8 weeks old) and immature (4 weeks old) donors, but there was no change in grafts from postnatal (10 days after birth) donors. When immature female mice were used as recipients, uNK cell differentiation was observed in grafts from both mature and immature donors, but decidualization and differentiation of uNK cells were not observed in the recipient uterus even in the presence of progesterone. These results suggest that uNK cell differentiation is not associated with the sexual maturation of recipients, and that the effect of progesterone on uNK cell differentiation is not direct, even though progesterone is an essential factor for uNK cell differentiation. When male mice were used as recipients, decidualization and differentiation of uNK cells were not observed in uterine grafts from normal mature mice. On the other hand, in castrated recipients uNK differentiation was induced in the graft, suggesting that uNK cell cannot fully differentiate in the presence of testosterone.
\end{abstract}

Key words: Uterine natural killer cell, Progesterone, Decidualization, Differentiation, Transplantation

(J. Reprod. Dev. 48: 561-566, 2002)

D uring pregnancy in humans, rodents and other species of mammals, a unique subset of lymphocytes predominates at the implantation sites [1]. In mice, the uterine lymphocytes called uterine NK (uNK) cells are characterized by the large granules stained by periodic acid Schiff (PAS), and are localized in the metrial grand and the decidua basalis of each placenta. The uNK cells are suggested as having a significant function in the maintenance of pregnancy, through placental vascular formation and modification $[2,3]$. The uNK cells differentiate in situ from bone marrow derived precursor cells that are small and agranular $[4,5]$. Following implantation, the precursors increase dramatically in both number and size and

Accepted for publication: June 12, 2002

Correspondence: Y. Kiso

gradually develop prominent cytoplasmic granules containing pore forming protein (perforin), granzymes and serine esterases [6, 7]. The uNK cells can produce several cytokines including IL-1, CSF-1, LIF, EGF, TNF- $\alpha$, and also INF- $\gamma$ [7-9]. The uNK precursors, Ly $49 \mathrm{G}^{+}$cells, are found in the uterus of infant mice at 2 weeks of age [10], but it is thought that the uterus has no long-term, resident uNK precursor pool, and that the precursors flow into the uterus during pregnancy. Thus, throughout adulthood, it appears that the major lymphocyte population of the uterus is replenished by precursors from other tissues [11].

The mechanism of uNK cell differentiation is still unknown. One of the sex steroid hormones, progesterone, is suggested to have a significant function in the differentiation of $\mathrm{uNK}$ cells, because 
Table 1. A list of the recipients and the donors

\begin{tabular}{llcccl}
\hline Recipient: & sex & sexual maturation & pregnant & P teatment & donor: sexual maturation (n) \\
\hline \multirow{2}{*}{ female } & mature & + & - & mature (4) / immature (4) / postnatal (3) \\
& & mature & - & + & mature (4) / immature (4) / postnatal (3) \\
& immature & - & + & mature (3) / immature (3) \\
& male & mature & - & + & mature (3) \\
& castrated & - & + & mature (3) \\
\hline
\end{tabular}

Each uterine graft was transplanted to each recipient. P: progesterone.

uNK cell development is wholly synchronized with the progesterone level $[12,13]$. In mice, a lot of uNK cells are also found in the pseudopregnant uterus after progesterone treatment. Furthermore, progesterone receptor (PR) expresses on murine uNK hybridomas, uterine epithelial cells and stromal cells [14]. Progesterone is known to regulate the production of cytokines and growth factors in the uterus during the estrus cycle and pregnancy. Thus, to establish if progesterone plays an essential role in the differentiation of uNK cells, we experimented using tissue grafts from uteri at different developmental stages.

\section{Materials and Methods}

\section{Animal}

ICR mice (CLEA JAPAN, Osaka) were used as both recipients and donors. Female mature, immature, and postnatal mice were used as uterine tissue donors to investigate the interaction between the uterine development and uNK cell differentiation. Mature or immature females, and intact mature male, or castrated mature male mice were used as recipients. Mice of 8 weeks old were regarded as mature because they cycled regularly, while those of 4 weeks old were regarded as immature because they did not cycle. Mice of 4 weeks old expressed PR in the endometrium, while mice of 10 days after birth did not, therefore, mice of 10 days after birth were designated as postnatal. Castrated male mice were prepared by removing testis and epididymis at 4 weeks after birth, and were used in this study at 8 weeks after birth.

\section{Transplantation of the uterine grafts}

Uterine tissue segments $\left(1 \mathrm{~mm}^{3}\right)$ were collected from the donors. These segments containing the endometrium were inserted into the subcapsular space of the left kidney. Mature mice were selected for estrus and paired with ICR males, and the morning of vaginal plug detection was designed as day 0 of pregnancy (Day 0). The uterine grafts were transplanted at Day 0, and sampled on Day 7, because 7 days is sufficient time for uNK differentiation. Transplantation of the uterine grafts to female immature, male mature, and castrated mice was performed on Day 0 , and the grafts were sampled on Day 7 . In these experiments $2 \mathrm{mg}$ progesterone (4-pregnene-3, 20dione; Sigma Chemicals Co., Japan) with $100 \mu \mathrm{l}$ vehicle (sesame oil) were injected under the skin from Day 0 to Day 6 every 24 hours. The combination of recipients and donors is listed in detail in Table 1. Decidualization of the grafts and differentiation of uNK cells within the grafts were investigated histologically and immunohistochemically. When females were used as recipient, the uteri of the recipients were also sampled and investigated in the same way.

\section{Histological analysis}

For light microscopy, the kidney containing the uterine graft was fixed in Bouin's solution and embedded in paraffin. Paraffin sections were made transversely through the graft and stained with periodic acid-Schiff (PAS) reagent. Decidualization of the uterine graft and the uNK cells with PASpositive granules were observed morphologically at each graft from different donors. The uterine tissues were prepared and observed in the same way.

\section{Immunohistochemistry}

To identify the PAS-positive cells in grafts as uNK cells, frozen sections were stained immunohistochemically by the avidin-biotin complex method (ABC kit; Vector Lab. Inc., Burlingame, CA, USA). Rat anti-mouse Ly49G2 antibody (Fujisawa Pharmacentical Co., Ltd, Osaka, Japan) was used as the primary antibody, 

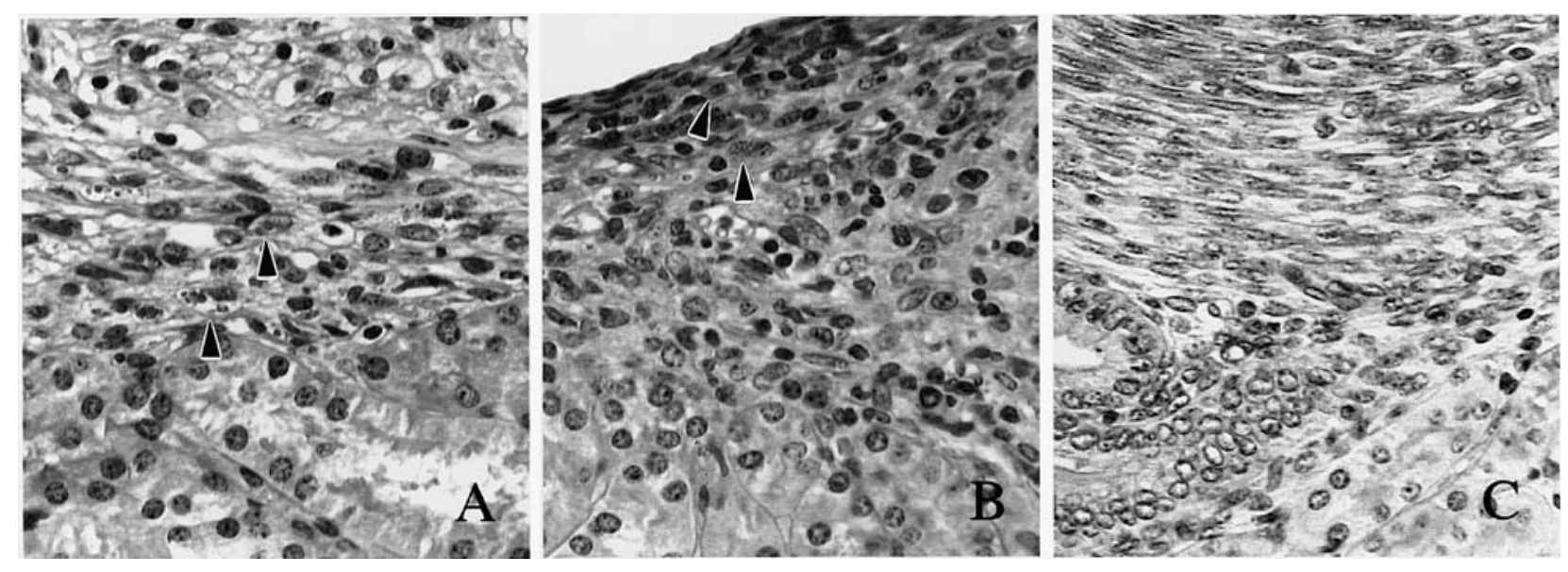

Fig. 1. Comparison of decidualization and differentiation of uNK cells in grafts from 3 kinds of donors. Decidualization and differentiation of uNK cells (arrows) were observed in the grafts from mature (A) and immature donors (B). No changes were observed in the graft from postnatal donors $(\mathrm{C})$. All changes were observed in the presence of progesterone. PAS stain. $\times 400$.

because Ly49G2 is one of the uNK surface markers [10]. After treatment for 30 min with $0.3 \%$ hydrogen peroxide to quench endogenous peroxidase and then treatment for 30 min with $2 \%$ normal goat serum as blocking solution, the sections were reacted with the primary antibody of $1 / 100$ dilution in PBS at 4 C overnight. Sections were then incubated with biotinylated goat anti-rat IgG (Vector Lab. Inc., Burlingame, CA, USA) of 1/ 200 dilution in PBS containing $2 \%$ normal goat serum at room temperature for $30 \mathrm{~min}$. Final incubation was carried out with avidin-horseradish peroxidase complex at room temperature for 30 min, and positive reactions were visualized with 3,3'-diaminobenzidine (DAB) at room temperature for $15 \mathrm{~min}$. Sections were counterstained with hematoxylin.

\section{Results}

Morphology of $u$ NK cells in graft

When female mice were used as recipients, decidualization and differentiation of uNK cells were observed in grafts from mature and immature donors (Fig. 1A, B), but there was no change in the grafts from postnatal donors (Fig. 1C, Table 2). The uNK cells in grafts from mature and immature donors could differentiate in the presence of progesterone. When using immature mice as recipients, decidualization and differentiation of uNK cells were not observed in the immature
Table 2. Decidualization and uNK cell differentiation in the uterine graft from 3 kinds of donors

\begin{tabular}{lcc}
\hline Donor & decidualization in graft & uNK in graft \\
\hline mature & + & + \\
immature & + & + \\
postnatal & - & - \\
\hline
\end{tabular}

Three kinds of recipients: pregnant mature, non-pregnant mature with progesterone treatment, and immature with progesterone treatment.

uterus even in the presence of progesterone (Fig. 2A-C, Table 3). When castrated male mice were used as recipients, decidualization and differentiation of uNK cells were observed in the grafts (Fig. 3A), but there was no change in the grafts of the normal mature recipients (Fig. 3B, Table 4).

Immunohistochemistry of $u N K$ cells in grafts

Ly49G2+ cells were observed in grafts from the mature and immature donors (Fig. 4).

\section{Discussion}

This study revealed that progesterone has indirect effects on the differentiation of uNK cells through decidual cells, and that the differentiation of uNK cells depends on the stage of uterine development. In the uterine grafts from the mature and immature donors, decidualization and uNK cell differentiation were observed in the presence of 

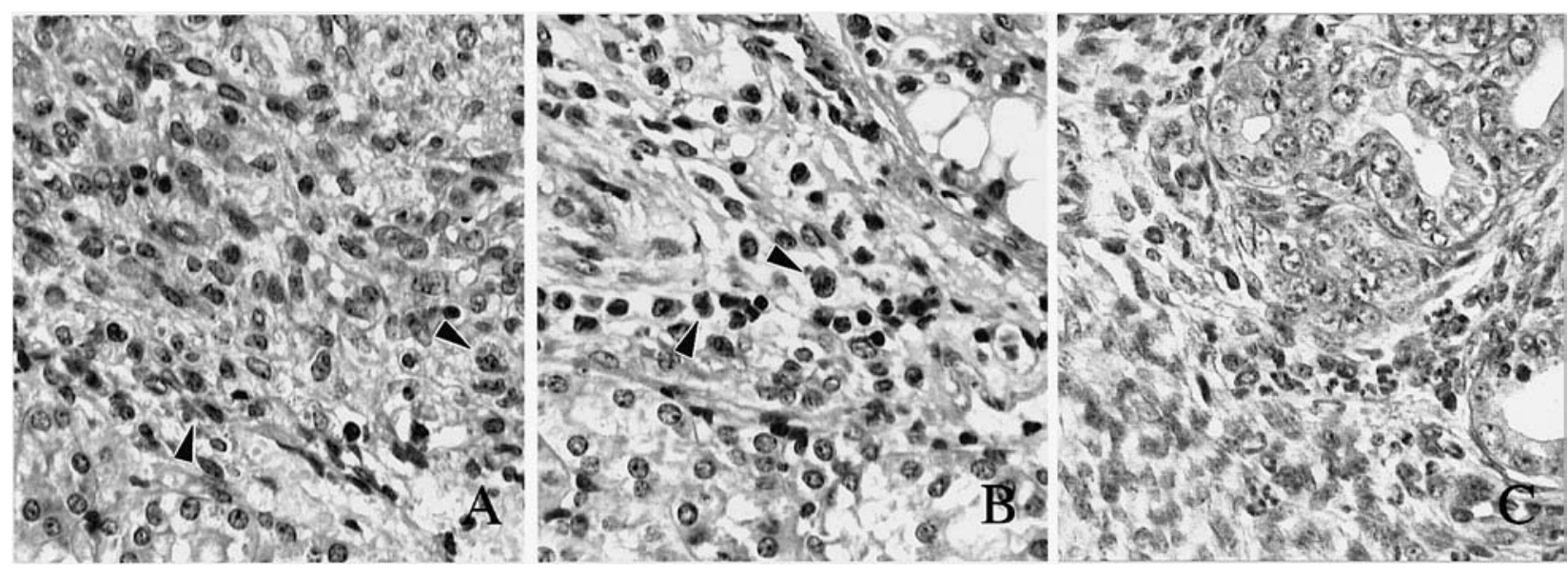

Fig. 2. Comparison of decidualization and differentiation of uNK cells in recipients uteri and grafts from 2 kinds of donors. When immature mice were used as recipients, decidualization and differentiation of uNK cells were (arrows) observed in grafts from mature (A) and immature donors (B). No changes were observed in the recipients uteri (C). PAS stain. $\times$ 400 .

Table 3. Decidualization and uNK cell differentiation in the uteri of recipients

\begin{tabular}{lcc}
\hline Recipient & decidualization in uterus & uNK in uterus \\
\hline mature & + & + \\
immature & - & - \\
\hline
\end{tabular}

Three kinds of donors: mature, immature and postnatal.

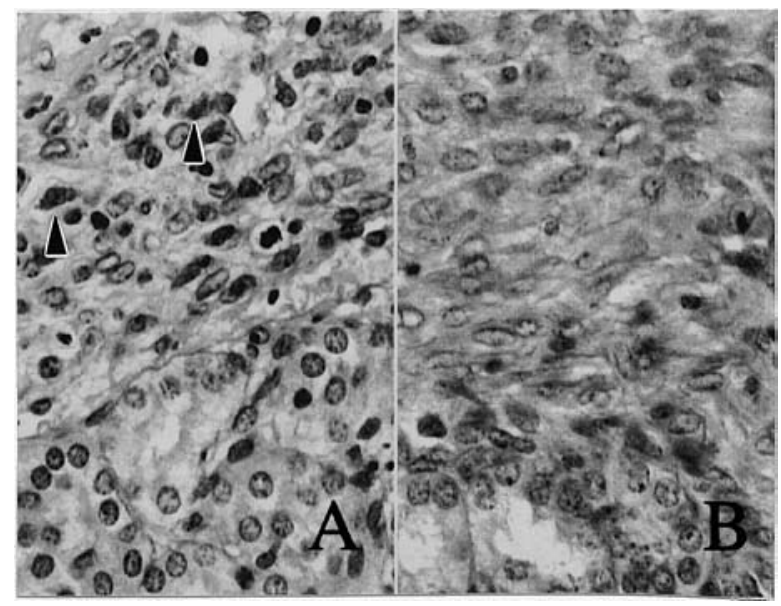

Fig. 3. Comparison of decidualization and differentiation of uNK cells in grafts that were transplanted into 2 kinds of male recipients. When castrated male mice were used as recipients, decidualization and differentiation of uNK cells (arrows) was observed in the graft in the presence of progesterone (A). When normal male mice were used as recipients, no changes were observed in the graft in the presence of progesterone (B). PAS stain. $\times 400$.
Table 4. Decidualization and uNK cell differentiation in the uterine graft transplanted into 2 kinds of male recipients

\begin{tabular}{lcc}
\hline Recipient & decidualization in graft & uNK in graft \\
\hline castrated & + & + \\
normal & - & - \\
\hline
\end{tabular}

Two kinds of male recipients: castrated male with progesterone treatment and normal male with progesterone treatment.

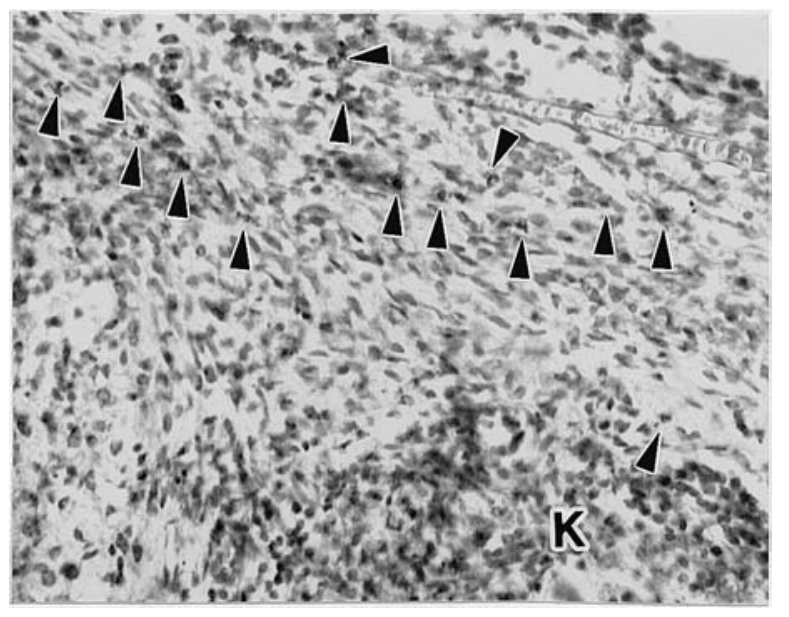

Fig. 4. Identification of uNK cells in a graft. Ly49G2 positive cells (arrows) present in a uterine graft. $\mathrm{K}$; kidney. Counterstained with hematoxylin. $\times 400$. 
progesterone, but not in the grafts from postnatal donors. In the mouse, uNK cell differentiation is synchronized with the blood level of progesterone [15]. This fact suggests that progesterone may have essential functions in uNK cell differentiation and proliferation. Human uNK cells could differentiate and proliferate, although they did not express progesterone receptor (PR) [16]. However, since progesterone acts on endometrial stromal cells, human uNK cells could have differentiated through signals from decidual cells $[17,18]$. Besides, in the human, decidualization of endometrial stromal cells occurs before differentiation of uNK cells in a successful pregnancy. Thus, it is suggested that in the human, progesterone is a significant factor in the induction of differentiation of uNK cells. Expression of PR in the murine uterus is synchronized with decidualization of endometrium [15]. In the mouse, PR expression on the uterine stroma was observed on Day 12-15 after birth [14, 19, 20], supporting our result that no change was observed in the grafts from postnatal donors. When immature mice were used as recipients, changes were not observed in the uterus of the recipient. However, decidualization and differentiation of
uNK cells were observed in uterine grafts from immature donors. Decidualization did not occur in the uterine stromal cells of immature recipients though they did express PR. Thus, decidualization in the uterine grafts from the immature donors was thought to be induced by the mechanical stimulation of the transplantation [21].

In this study, we used male mice as recipients to investigate the effects of progesterone in the presence of testosterone. When male mice were used as recipients, decidualization and differentiation of uNK cells were not observed in uterine grafts. However, uNK differentiation was induced in the grafts of castrated recipients. These results suggest that uNK cells cannot fully differentiate in the presence of testosterone even if progesterone is given.

\section{Acknowledgement}

This study was supported in part by a Grant-inaid for Scientific Research (A, No. 12306015) of Ministry of Culture, Sports, Science and Technology (to Y. K.).

\section{References}

1. Pace D, Morrison L, Bulmer JN. Proliferative activity in endometrial stromal granulocytes throughout menstrual cycle and early pregnancy. $J$ Clin Pathol 1989; 42: 35-39.

2. Chantakru S, Kuziel WA, Maeda N, Croy BA. A study on the density and distribution of uterine natural killer cells at mid pregnancy in mice genetically-ablated for CCR2, CCR 5 and the CCR5 receptor ligand, MIP-1alpha. J Reprod Immunol 2001; 49: 33-47.

3. Burnett TG, Hunt JS. Nitric oxide synthase-2 and expression of perforin in uterine NK cells. J Immunol 2000; 164: 5245-5250.

4. Lysiak JJ, Lala PK. In situ localization and characterization of bone marrow-derived cells in the decidua of normal murine pregnancy. Biol Reprod 1992; 47: 603-613.

5. Guimond MJ, Wang B, Croy BA. Engraftment of bone marrow from severe combined immunodeficient (SCID) mice reverses the reproductive deficits in natural killer cell-deficient tg epsilon 26 mice. J Exp Med 1998; 187: 217-223.

6. Parr EL, Parr MB, Zheng LM, Young JD. Mouse granulated metrial gland cells originate by local activation of uterine natural killer lymphocytes. Biol Reprod 1991; 44: 834-841.

7. Croy BA, Reed N, Malashenko BA, Kim K, Kwon BS. Demonstration of YAC target cell lysis by murine granulated metrial gland cells. Cell Immunol 1991; 133: 116-126.

8. Platt JS, Hunt JS. Interferon-gamma gene expression in cycling and pregnant mouse uterus: temporal aspects and cellular localization. J Leukoc Biol 1998; 64: 393-400.

9. Kusakabe K, Okada T, Sasaki F, Kiso Y. Cell death of uterine natural killer cells in murine placenta during placentation and preterm periods. J Vet Med Sci 1999; 61: 1093-1100.

10. Kiso Y, McBey BA, Mason L, Croy BA. Histological assessment of the mouse uterus from birth to puberty for the appearance of LGL-1+ natural killer cells. Biol Reprod 1992; 47: 227-232.

11. Croy BA, Ashkar AA, Chantakru S. Minhas K, Greenwood DJ. Cloned animal and placentation. In: Michel RR, Yanagimachi R, Kariya T, Hasizume K (eds.), The Biology of Uterine Natural Killer Cells 
During Early Gestation. Tokyo: Yokendo Ltd; 2001: 78-82.

12. King A, Wellings V, Gardner L, Loke YW. Immunocytochemical characterization of the unusual large granular lymphocytes in human endometrium throughout the menstrual cycle. Hum Immunol 1989; 24: 195-205.

13. Bulmer JN, Morrison L, Longfellow M, Ritson A, Pace D. Granulated lymphocytes in human endometrium: histochemical and immunohistochemical studies. Hum Reprod 1991; 6: 791-798.

14. van den Heuvel M, McBey BA, Hahnel AC, Croy BA. An analysis of the uterine lymphocyte-derived hybridoma cell line GWM 1-2 for expression of receptors for estrogen, progesterone and interleukin 2. J Reprod Immunol 1996; 31: 37-50.

15. Peel S, Stewart IJ, Bulmer D. Experimental evidence for the bone marrow origin of granulated metrical gland cells of the mouse uterus. Cell Tissue Res 1983; 233: 647-656.

16. King A, Gardner L, Loke YW. Evaluation of oestrogen and progesterone receptor expression in uterine mucosal lymphocytes. Hum Reprod 1996; 11:
1079-1082.

17. Lessey BA, Killam AP, Metzger DA, Haney AF, Greene GL, McCarty KS. Immunohistochemical analysis of human uterine estrogen and progesterone receptors throughout the menstrual cycle. J Clin Endocrinol Metab 1988; 67: 334-340.

18. Bergqvist A, Ljungberg O, Skoog L. Immunohistochemical analysis of oestrogen and progesterone receptors in endometriotic tissue and endometrium. Hum Reprod 1993; 8: 1915-1922.

19. Uotinen N, Puustinen R, Pasanen S, Manninen T, Kivineva M, Syvala H, Tuohimaa P, Ylikomi T. Distribution of progesterone receptor in female mouse tissues. Gen Comp Endocrinol 1999; 115: 429441.

20. Ohta Y, Sato T, Iguchi T. Immunocytochemical localization of progesterone receptor in the reproductive tract of adult female rats. Biol Reprod 1993; 48: 205-213.

21. Wewer UM, Damjanov A, Weiss J, Liotta LA, Damjanov I. Mouse endometrial stromal cells produce basement-membrane component. Differentiation 1986; 32: 49-58. 